\title{
Sero-Prevalence of Paratuberculosis (Johne's Disease) in Cattle Population of South-Western Bangalore Using ELISA Kit ${ }^{*}$
}

\author{
Anvita Gupta ${ }^{1 \#}$, Sobha M. Rani ${ }^{2}$, Pushpa Agrawal ${ }^{1}$, Praveen Kumar Gupta ${ }^{1}$ \\ ${ }^{1}$ Department of Biotechnology, R.V. College of Engineering, Bangalore, India \\ ${ }^{2}$ Department of Seroepidemiology, Institute of Animal Health \& Veterinary Biologicals, Bangalore, India \\ Email: \#anvita26@gmail.com
}

Received September 1, 2012; revised October 1, 2012; accepted October 22, 2012

\begin{abstract}
Johne's disease or paratuberculosis is a chronic mycobacterial infection that affects cattle, sheep, goats and other ruminants, adversely, leading to huge economic losses throughout the world. The estimation of sero-prevalence of this disease in the cattle population of south-western Bangalore, Karnataka, using an immunological assay and statistical analyses, was the objective of this study. One of the diagnostic tools used to detect an antigen or an antibody in animal serum or milk is the Enzyme Linked Immuno-Sorbent Assay, which has been widely used in the research and diagnosis of animal and human diseases as its accuracy is of nanogram-picogram/milliltre level. In the present study, indirectELISA was used to diagnose and estimate the sero-prevalence of paratuberculosis in cattle showing diarrhoea and/or anaemia, at 5 local dairy farms in south-west Bangalore, India. Out of 350 bovine serum samples, $53(15.14 \%)$ were positive, 55 milk samples out of 300 were found positive (18.33\%) for antibody against Johne's disease by indirect ELISA. The positive samples were then confirmed by direct smear examination of dung by Ziehl-Neelsen staining. Statistical analyses were carried out to indicate the seroprevalence of Johne's disease in the cattle population of this region to be $15 \pm 10 \%$, taking a confidence interval of $95 \%$. The results emphasize the need to prevent the further spread of infection to other susceptible animals and humans as the causative organism, Mycobacterium avium subsp. paratuberculosis is implicated in Crohn's disease, an irritable bowel syndrome in humans.
\end{abstract}

Keywords: Johne's Disease; Mycobacterium avium subsp. paratuberculosis; ELISA

\section{Introduction}

Johne's disease (JD), caused by Mycobacterium avium subsp. paratuberculosis, is one of the most prevalent in many countries worldwide and economically important diseases of livestock and other ruminants. However, it largely goes unnoticed as its symptoms may be unfamiliar to most farmers and clinicians. JD was first diagnosed in India in 1913 at Hissar followed by reports from different parts of the country with incidence ranging from $1.78 \%$ to $1.9 \%$, indicated by [1]. Latest reports [2] reveal an increased sero-prevalence of JD, world wide ranging from $15 \%$ to $78 \%, 68.1 \%$ of US dairy farms are infected with Mycobacterium avium subsp. paratuberculosis (MAP) and also suggests that at least one out of every four United States dairy may have a relatively high percentage of Johne's-infected cows in their herds. Netherlands recorded 55\% prevalence [1] and in Denmark re-

\footnotetext{
*Competing interests: the authors declare that they have no competing interests.

${ }^{\#}$ Corresponding author.
}

ported $47 \%$ prevalence of JD [3]. Approximately $29.0 \%$ ( $28.6 \%$ in buffalo and $29.8 \%$ in cattle) of sero-prevalence of JD is reported in northern India. [4] reported seroprevalence of $31.9 \%$ and $23.3 \%$ in Uttar Pradesh and Punjab states respectively. The apparent prevalence of JD is $13.39 \%$ and $16.26 \%$ in Gujarat and Andhra Pradesh respectively [5].

Johne's disease or paratuberculosis in animals is incurable, chronic wasting and debilitating disease characterized by weight loss and profuse diarrhoea. Paratuberculosis is principally a disease of ruminants but disease is also noticed in non ruminant animal species (pigs, dogs, horses, cats, etc.) including free ranging animals (Blue bull, deer, rabbits) and primates [6]. Johne's disease adversely affects animal productivity leading to huge economic losses and has been recognized as one of the most costly infectious disease of dairy cattle in the world [7]. MAP shows a distinct tissue tropism and causes chronic inflammation of the intestine even if administered subcutaneously or intravenously. The regions of the gastro-intestinal tract usually affected are the terminal ileum 
and colon with segmental lesions as well as rectal involvement. The gut wall is thickened, the mucosa is swollen with occasional ulcers and the regional mesenteric lymph nodes are enlarged. Microscopically, MAP disease in animals shows a broad range of histopathological characteristics in the gut wall, from pluribacillary disease with abundant Ziehl-Neelsen positive acidfast bacilli in intestinal macrophages, to an extreme paucimicrobial form with no visible acid-fast organisms and florid chronic granulomatous inflammation [8]. Paratuberculosis appears in a range of forms from a disease with high prevalence and significant mortality through to one with very low prevalence and little obvious morbidity or mortality [9]. The morbidity rates are very high and distributed over a period of time thus losses in production go unnoticed and have never been estimated in India despite low per animal productivity as reported by [10]. Systematic surveys of MAP infection have not been undertaken though JD is endemic in domestic livestock [11]. After infection has taken place but before clinical symptoms are apparent, the infected animal likely sheds bacteria [12]. These bacteria can contaminate the calving and housing areas and infect other animals in the herd. The evidence by [13], suggests that MAP shed in the milk from dairy cattle may cause Crohn's disease in humans as pasteurization does not kill the bacteria.

Control and management of Johne's disease are complicated by the lack of a rapid, sensitive diagnostic test for identifying diseased animals before clinical signs develop. Paratuberculosis is not only chronic but is also currently incurable and often remains in a subclinical state for years as reported by [14]. Thus, it is important to diagnose the disease as early as possible to reduce losses and also spread of infection to susceptible animals and humans. The diagnostic tests to detect infection with MAP can be categorized into those that identify the organism and those that identify an immunological reaction to the organism.

The immunological test that is widely available and commonly used is the Enzyme Linked Immunosorbant Assay (ELISA), which detects antibody in serum [15] or milk [16] that correlates with an antibody response to MAP. The ELISAs have been desirable tests to use because of their ease of sample collection (blood or milk), rapid test results (within a week), and relatively low cost. Its sensitivity is greater than that of the Complement Fixation test (CFT) in subclinically infected carriers. The specificity of the ELISA is increased by Mycobacterium phlei absorption of sera. [17] stated that paratuberculosis can also be diagnosed by detection of serum antibodies (serological tests), by identification of bacteria (faecal cultures), and by PCR using DNA probes.

The diagnosis of Johne's disease in animals may help in prevention of spread to susceptible animals in the herd and also humans. Hence the present study was under taken with the objective to estimate the incidence of JD infection in cattle population of south-west Bangalore using ELISA (Institut Pourquier, ELISA Paratuberculosis Antibody screening). The presence of MAP was confirmed by direct smear examination of positive samples by Ziehl-Neelsen staining.

\section{Materials and Methods}

A stratified two-stage random sampling procedure was employed to obtain reasonably valid and precise prevalence estimates from each of the herds at the 5 local dairy farms [18]. Approximately 70 cows from each of the 5 farms were randomly selected for this survey. This number of animals was derived from sample size calculations for estimation of prevalence of diseased animals in a population. The formula assumed an estimated average prevalence of disease of $10 \%$, an allowable error of $10 \%$, and a confidence level of $95 \%$, using sample size calculations as described by [19].

\subsection{Collection of Samples}

\subsubsection{Blood Samples}

About 350 bovine blood samples were collected from the Red Sindhi breed of cows which showed signs of diarrhoea and/or anaemia, at 5 local dairy farms in southwest Bangalore, having no previous history of paratuberculosis. These 3 - 4 year-old cows were tested once a year for paratuberculosis by CFT method. Aged cows of 15 - 18 years of age were excluded from this study as they were fewer in number and were isolated from the young lactating female cows. About $9 \mathrm{ml}$ of blood was collected aseptically from the jugular vein of each animal in a vacutainer with serum clot activator. The tubes were kept in upright position at room temperature for about 2 hrs. The separated serum was collected in a screw capped plastic vials and transported to the laboratory.

\subsubsection{Milk Samples}

About 300 milk samples were collected from lactating cows of the same herd as mentioned above.

\subsubsection{Dung Samples from Cows Tested Positive by ELISA}

Approximately $2 \mathrm{~g}$ of dung sample was taken and mixed with $10 \mathrm{ml}$ of saline. The solution was centrifuged at 800 rpm for 20 minutes and the pellet was discarded. The collected supernatant and intermittent were centrifuged again at $800 \mathrm{rpm}$ for 20 minutes. Then the pellet was collected and stored at $4^{\circ} \mathrm{C}$.

\subsection{Procedure}

ELISA kit (from Institut Pourquier, France) was used for 
the detection of Mycobacterium paratuberculosis antibodies in serum and milk samples. The 350 serum samples were pooled in to form 70 samples in batches of 5 for efficient screening. The pooled samples found positive, were again tested individually to determine the exact positive serum sample. To eliminate the cross-reactions with atypical mycobacteria, samples to be tested were diluted and incubated in a dilution buffer containing a Mycobacterium phlei extract. The controls, serum and plasma were diluted to $1 / 20$ in dilution buffer in micro tubes. The milk samples were diluted to $1: 2$ in dilution buffer in micro tubes. These tubes were shaken and incubated for 15 minutes at $+21^{\circ} \mathrm{C}\left( \pm 5^{\circ} \mathrm{C}\right)$.

The contents of the microtubes were dispensed in the 96 well plates using a multi-dispensing pipette (Transferpette ${ }^{\mathbb{B}}$ ). About $100 \mu \mathrm{l}$ of diluted negative control was added to well A1, $100 \mu \mathrm{l}$ of diluted positive control was added to wells B1 and C1, and $100 \mu \mathrm{l}$ of each diluted sample (serum, plasma or milk) to test per well (only one well per sample to test) was added. The contents of the wells were homogenized by gently shaking the plate in a plate shaker. The plate was covered (with a lid, aluminium or an adhesive foil) and incubated for 45 minutes ( \pm 3 minutes) at $+21^{\circ} \mathrm{C}\left( \pm 5^{\circ} \mathrm{C}\right)$, after which, the wells were washed with the washing buffer, manually three times by a flick-off method.

The conjugate was diluted to $1 / 100$ with the "Dilution Buffer 1" (provided in the kit) and $100 \mu \mathrm{l}$ of this diluted conjugate was added per well. The plate was covered (with a lid) and incubated for 30 minutes ( \pm 3 minutes) at $+21^{\circ} \mathrm{C}\left( \pm 5^{\circ} \mathrm{C}\right)$. The plate was washed again by the same method. Then, $100 \mu l$ of the "revelation solution" was added to all the wells of the plate and incubated at room temperature for 10 minutes, after which, $100 \mu \mathrm{l}$ of "stop solution" was dispensed per well. The plate was shaken gently until the colored solution homogenized.

To confirm the results of ELISA, a direct smear examination of dung samples of cows tested positive by ELISA was carried out using the Ziehl-Neelsen method. The pellet was smeared in a glass slide and air dried. The smear was covered carbalfuschsin and steamed over boiling water for 10 minutes. After washing, the slide was decolorized with $5 \% \mathrm{H}_{2} \mathrm{SO}_{4}$ for 2 minutes. The slide was rinsed with water to stop the decolorization action. Then, the smear was counterstained with methylene blue for 30 seconds. After washing, blot dried and examined under oil immersion.

\subsection{ELISA Analysis}

The microplate reader was blanked on air and the optical densities were read at $450 \mathrm{~nm}$. The results were considered accepted if the ratio between the mean O.D (Optical ensity) at $450 \mathrm{~nm}$ value of the positive control and O.D value of the negative control was $\geq 3.00$. The ratio Serum/Plasma (S/P) was calculated for each sample as follows (see the ratio below):

For serum samples with an $\mathrm{S} / \mathrm{P} \leq 60 \%$, was considered to be from an animal, which had not been infected by MAP. Any sample with an S/P between $60 \%-70 \%$ was considered as doubtful. Any sample with an $\mathrm{S} / \mathrm{P} \geq 70 \%$ was considered to be coming from an animal which had been infected by MAP. For milk sample with an $\mathrm{S} / \mathrm{P} \leq$ $30 \%$, was considered to be from an animal which had not been infected by MAP. Any sample with an S/P between $30 \%-40 \%$ was considered as doubtful. Any sample with an $\mathrm{S} / \mathrm{P} \geq 40 \%$ was considered to be coming from an animal which had been infected by MAP.

\subsection{Statistical Analyses}

Animal and herd level descriptive statistics were calculated to determine the proportion of cattle and proportion of herds that were infected with MAP. Herd level prevalence was calculated using two definitions of positive herds for MAP: 1) having at least 1 test positive animal; and 2) having at least 2 test positive animals [2]. Using formulae previously described [19], the estimated true herd prevalence and $95 \%$ confidence interval (CI), correcting for test sensitivity and specificity for the Pourquier ELISA for MAP, were calculated.

\section{Results}

Table 1 shows the proportion (and 95\% CI) of animals considered to be MAP-positive, the proportion of herds with at least 1 and 2 positive animals, and the average prevalence of infection in herds with at least 1 and 2 positive animals. We found that 53 serum samples were positive for paratuberculosis from a total of 350 bovine serum samples (15.14\%). Also, 55 samples were found positive $(18.33 \%)$ for the same antibody from a total of 300 bovine milk samples. The smear from dung samples revealed the presence of the acid fast organism by Ziehl-Neelsen staining. Under oil immersion, MAP stains bright red and stand out clearly against a blue background (Figure 1). The estimated true herd prevalence and $95 \% \mathrm{CI}$, correcting for test sensitivity and specificity, was determined to be $15 \% \pm 10 \%$.

\section{Discussion and Conclusions}

There have been very few research papers on the sero-

$$
\mathrm{S} / \mathrm{P}=100 \times \frac{(\text { O.D } 450 \mathrm{~nm} \text { of the sample }- \text { O.D } 450 \mathrm{~nm} \text { of the negative control) }}{(\text { meanO.D } 450 \mathrm{~nm} \text { of the positive control }- \text { O.D } 450 \mathrm{~nm} \text { of the negative control) }}
$$


Table 1. Animal and herd level seroprevalence results for Mycobacterium paratuberculosis.

\begin{tabular}{cccccc}
\hline & $\begin{array}{c}\text { Animals }+^{\mathrm{a}} \\
\mathrm{p}(95 \% \mathrm{CI})\end{array}$ & $\begin{array}{c}\text { Herds } 1+^{\mathrm{b}} \\
\mathrm{p}(95 \% \mathrm{CI})\end{array}$ & $\begin{array}{c}\text { Herds } 2+^{\mathrm{e}} \\
\mathrm{p}(95 \% \mathrm{CI})\end{array}$ & $\begin{array}{c}+ \text { in Herds } 1+^{\mathrm{d}} \\
\mathrm{p}(95 \% \mathrm{CI})\end{array}$ & $\begin{array}{c}+ \text { in Herds 2 }+^{\mathrm{e}} \\
\mathrm{p}(95 \% \mathrm{CI})\end{array}$ \\
\hline Farm 1 & $1.4 \%(0.9-1.95)$ & $21.5 \%(16-26.9)$ & $8.3 \%(4.4-12.2)$ & $2.9 \%(2.3-3.5)$ & $4.3 \%(3.5-5.05)$ \\
Farm 2 & $1.7 \%(0.8-2.6)$ & $21.7 \%(12.5-31)$ & $11.2 \%(2-20.4)$ & $3.9 \%(1.9-6.0)$ & $5.5 \%(3.2-7.9)$ \\
Farm 3 & $1.92 \%(0.85-3.0)$ & $26.7 \%(17.2-36)$ & $8.4 \%(1.3-15.4)$ & $2.8 \%(1.85-3.8)$ & $4.1 \%(2.3-5.9)$ \\
Farm 4 & $0.82 \%(0.35-1.3)$ & $16.7 \%(7.7-25.6)$ & $8.4 \%(1.3-15.4)$ & $2.5 \%(1.9-3.1)$ & $3.2 \%(2.4-4.0)$ \\
Farm 5 & $0.95 \%(0.3-1.6)$ & $19.8 \%(10.5-29)$ & $8.3 \%(4.4-12.2)$ & $2.9 \%(2.3-3.5)$ & $4.1 \%(2.3-5.9)$ \\
\hline
\end{tabular}

p-proportion; CI-confidence interval, ${ }^{a}$ Animals testing positive, ${ }^{b}$ Herds with at least one animal testing positive, ${ }^{c}$ Herds with at least two animals testing positive, ${ }^{\mathrm{d}}$ Animals testing positive in herds with at least one animal testing positive, ${ }^{\mathrm{e}}$ Animals testing positive in herds with at least two animals testing positive. Animal and herd level descriptive statistics were calculated to determine the proportion of cattle and proportion of herds that were infected with MAP. Herd level prevalence was calculated using two definitions of positive herds for MAP: 1) having at least 1 test positive animal; and 2) having at least 2 test positive animals [2]. Using formulae previously described [19], the estimated true herd prevalence and 95\% confidence interval (CI), correcting for test sensitivity and specificity for the Pourquier ELISA for MAP, were calculated.

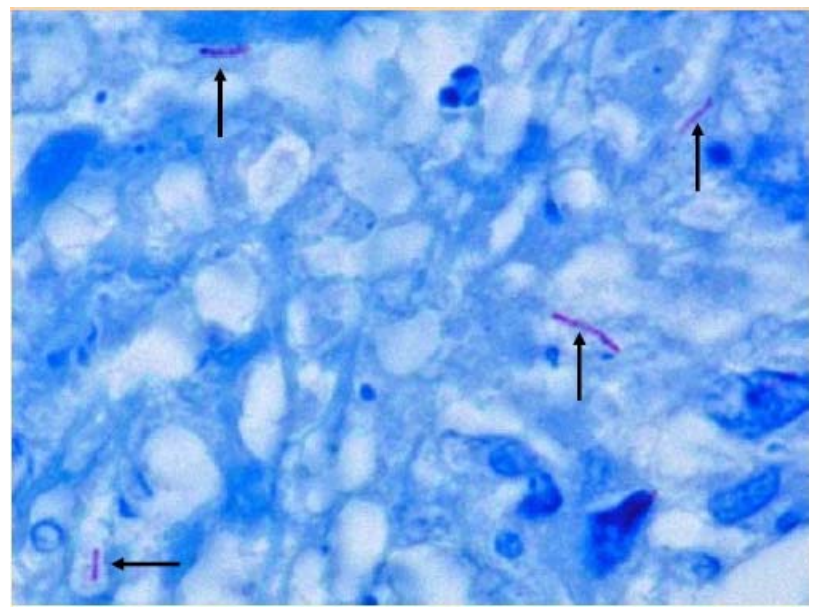

To confirm the results of ELISA, a direct smear examination of dung samples of cows tested positive by ELSIA was carried out using the Ziehl-Neelsen method. The pellet was smeared in a glass slide and air dried. The smear was covered carbalfuschsin and steamed over boiling water for 10 minutes. After washing, the slide was decolorized with $5 \% \mathrm{H}_{2} \mathrm{SO}_{4}$ for 2 minutes. The slide was rinsed with water to stop the decolorization action. Then, the smear was counterstained with methylene blue for 30 seconds. After washing, blot dried and examined under oil immersion. Under oil immersion, MAP stains bright red and stand out clearly against a blue background.

Figure 1. Arrows showing Mycobacterium avium subsp. paratuberculosis (MAP) observed under microscope.

prevalence of paratuberculosis in cattle population in Karnataka state of India. This is the first report on the estimation of prevalence of the disease in south-western Bangalore, Karnataka, India. The presence of specific antibodies to MAP in serum and milk samples from diarrheic and/or anemic animals indicates sub clinical stage of infection in the herd was detected by Indirect-ELISA. This study confirms that the ELISA test is one of the most reliable diagnostic tools for detection antibodies to MAP in animals. It's sensitivity and less time consumption justifies its widespread use as a herd screening test. The results are in corroboration with the findings of [3]. The direct examination of smear from the dung and tissue samples collected from cattle by Ziehl-Neelsen stain- ing revealed acid fast organism presence. The findings are in accordance with [20] to observe the acid fast staining technique could detect $25 \%$ - $40 \%$ cases of Johne's disease. The results of the study revealed that statistical analyses combined with an I-ELISA test provides the presumptive diagnosis of MAP infection in the herd and the need for control measures to prevent further spread of infection to susceptible species and humans.

This study is the first to report and estimate the seroprevalence of paratuberculosis in cattle population of south-western Bangalore, India, and hence will certainly contribute in the management and eradication of the disease from this region.

\section{Acknowledgements}

The authors wish to express their appreciation to Dr. G. Krishnappa, Director of Institute of Animal Health \& Veterinary Biologicals, Bangalore, for granting permission for this research.

\section{Ethical Approval}

This study has been conducted while complying with all ethical guidelines prescribed by the Indian government and has received ethical approval from the research institute.

\section{REFERENCES}

[1] J. Muskens, H. W. Barkema, E. Russchen, K. van Maanen, Y. H. Schukken and D. Bakker, "Prevalence and Regional Distribution of Paratuberculosis in Dairy Herds in the Netherlands," Veterinary Microbiology, Vol. 77, No. 3-4, 2000, pp. 253-261. doi:10.1016/S0378-1135(00)00310-2

[2] National Animal Health Monitoring System, Center for Epidemiology and Animal Health, "Johne's Disease on US Dairy Operations," Fort Collins, Colorado, 1997.

[3] S. S. Nielsen, S. M. Thamsborg, H. Houe and V. Bitsch, "Bulk-Tank Milk ELISA Antibodies for Estimating the Prevalence of Paratuberculosis in Danish Dairy Herds," 
Preventive Veterinary Medicine, Vol. 44, No. 1-2, 2000, pp. 297-297.

[4] S. V. Singh, A. V. Singh, R. Singh, S. Sharma, N. Shukla, S. Misra, P. K. Singh, J. S. Sohal, H. Kumar, P. K. Patil, P. Misra and K. S. Sandhu, "Sero-Prevalence of Johne's Disease in Buffaloes and Cattle Population of North India Using Indigenous ELISA Kit Based on Native Mycobacterium avium Subspecies paratuberculosis 'Bison Type' Genotype of Goat Origin," Comparative Immunology, Microbiology and Infectious Diseases, Vol. 31, No. 5, 2000, pp. 419-433. doi:10.1016/j.cimid.2007.06.002

[5] J. M. Lall, "John's Disease in Cattle, Sheep and Goats," Issue 19 of I. C. A. R. Research Series, Indian Council of Agricultural Research, 1963.

[6] R. J. Chiodini, "Crohn's Disease and the Mycobacterioses: A Review and Comparison of Two Disease Entities," Clinical Microbiology Reviews, Vol. 2, No. 1, 1989, pp. 90-117.

[7] L. Hasonova and I. Pavlik, "Economic Impact of Paratuberculosis in Dairy Cattle Herds: A Review," Veterinarni Medicina, Vol. 51, No. 5, 2006, pp. 193-211.

[8] J. Hermon-Taylor and F. A. K. El-Zaatari, "The Mycobacterium avium subspecies paratuberculosis (MAP) Problem and Its Relation to the Causation of Crohn's Disease," A Guide to Public Health Consequences, Monitoring and Management IWA Publishing, London, 2004, pp. 74-94.

[9] R. J. Whittington and E. S. G. Sergeant, "Progress towards Understanding the spread, Detection and Control of Mycobacterium avium subsp paratuberculosis in Animal Populations," Australian Veterinary Journal, Vol. 79, No. 4, 2001, pp. 267-278. doi:10.1111/j.1751-0813.2001.tb11980.x

[10] M. I. Barbaruah and A. K. Joseph, "India: Dairy Giant Walking Barefoot," FAO-RAP Technical Meeting, 2008, pp. 17-20.

[11] N. P. Kurade, B. N. Tripathi, K. Rajukumar and N. S. Parihar, "Sequential Development of Histologic Lesions and their Relationship with Bacterial Isolation, Faecal Shedding, and Immune Responses during Progressive Stages of Experimental Infection of Lambs with Mycobacterium avium subsp. paratuberculosis," Veterinary Pathology, Vol. 41, No. 3, 2008, pp. 378-387. doi:10.1354/vp.41-4-378

[12] A. W. Lepper, C. R. Wilks, M. Kotiw, J. T. Whitehead

\section{Abbreviations}

Enzyme Linked Immuno-Sorbent Assay, ELISA; Johne's Disease, JD;

Mycobacterium avium subsp. paratuberculosis, MAP; and K. S. Swart, "Sequential Bacteriological Observations in Relation to Cell-Mediated and Humoral Antibody Responses of Cattle Infected with Mycobacterium paratuberculosis and Maintained on Normal or High Iron Intake," Australian Veterinary Journal, Vol. 66, No. 2, 1989, pp. 50-55. doi:10.1111/j.1751-0813.1989.tb03015.x

[13] P. Beard, M. J. Daniels, D. Henderson, A. A. Pirie, K. Rudje, D. Buxton, S. Rhind, A. Greig, M. R. Hutchings, I. McKendrick, K. Stevenson and J. M. Sharp, "Paratuberculosis Infection in Non Ruminant Wildlife in Scotland," Journal of Clinical Microbiology, Vol. 39, No. 4, 2001, pp. 1517-1521. doi:10.1128/JCM.39.4.1517-1521.2001

[14] P. M. Cousens, "Model for Immune Responses to Mycobacterium avium subspecies paratuberculosis in Cattle," Infection and Immunity, Vol. 72, No. 6, 2004, pp. 30893096. doi:10.1128/IAI.72.6.3089-3096.2004

[15] Y. Yokomizo, R. S. Merkal and P. A. Lyle, "EnzymeLinked Immunosorbent Assay for Detection of Bovine Immunoglobulin G1 Antibody to a Protoplasmic Antigen of Mycobacterium paratuberculosis," American Journal of Veterinary Research, Vol. 44, No. 11, 1983, pp. 22052207.

[16] L. E. Hardin and J. G. Thorne, "Comparison of Milk with Serum ELISA for the Detection of Paratuberculosis in Dairy Cows," Journal of the American Veterinary Medical Association, Vol. 209, No. 1, 1996, pp. 120-122.

[17] J. R. Stabel, “An Improved Method for the Cultivation of Mycobacterium paratuberculosis from Bovine Fecal Samples and Comparison to Three Other Methods," Journal of Veterinary Diagnostic Investigation, Vol. 9, No. 4, 1998, pp. 357-380.

[18] J. A. VanLeeuwen, G. P. Keefe, R. Tremblay, C. Power and J. J. Wichtel, "Seroprevalence of Infection with $M y$ cobacterium avium subspecies paratuberculosis, Bovine Leukemia Virus, and Bovine Viral Diarrhea Virus in Maritime Canada Dairy Cattle," Canadian Veterinary Journal, Vol. 42, No. 3, 2001, pp. 193-198.

[19] S. W. Martin, A. H. Meek and P. Willeberg, "Principles and Methods," In: Ames, Ed., Veterinary Epidemiology, Iowa State University Press, Oxford, 1987.

[20] W. L. McDonald, S. E. Ridge, A. F. Hope and R. J. Condron, "Evaluation of Diagnostic Tests for Johne's Disease in Young Cattle," Australian Veterinary Journal, Vol. 77, No. 2, 1999, pp. 113-119.

Confidence Interval, CI;

Complement Fixation test, CFT;

Polymerase Chain Reaction, PCR;

Optical Density, OD;

Serum/Plasma, S/P. 